\title{
REDESAIN SEMINARI MENENGAH PASTOR MERAUKE (PENDEKATAN ARSITEKTUR MODERN TROPIS)
}

\author{
Anton Topan ${ }^{*}{ }^{1}$, Henry Soleman Raubaba ${ }^{1}$, Gregorius Ulahayanan ${ }^{1}$ \\ ${ }^{1}$ Teknik Arsitektur, Fakultas Teknik, Universitas Musamus, Merauke \\ Jl. Kamizaun Mopah Lama Merauke, Papua, 99611 \\ *Email: topan.anton29@gmail.com
}

\begin{abstract}
Abstrak
Seminari Menengah Pastor Bonus yang berlokasi di kompleks SMA YPPK Yos Sudarso Merauke saat ini belum memiliki fasilitas yang lengkap dari segi fungsi ruang maupun penataan bangunan secara optimal. Redesain Seminari Menengah Pastor Bonus di Merauke diharapkan dapat mengembangkan luasan site seminari yang ada, sehingga dapat memenuhi kebutuhan fasilitas yang sesuai fungsi dan zonasi. Tujuan Penelitian ini yaitu meredesain Seminari Menengah Pastor Bonus Merauke yang mengutamakan kejelasan fungsi dan zonasi melalui pendekatan arsitektur modern tropis, serta menata massa bangunan sesuai bentuk tapak dengan mempertimbangkan sirkulasi. Metode yang digunakan dalam pennelitian ini yaitu metode observasi/pengamatan langsung ke lokasi penelitian, wawancara pada pihak seminari dan Keuskupan Agung Merauke yang memberikan arahan untuk pengembangan kawasan dan peningkatan kapasitas dari fasilitas seminari. Hasil yang diperoleh digunakan sebagai acuan peningkatan fasilitas pengelola, fasilitas edukasi, fasilitas minat bakat, fasilitas religi, fasilitas hunian dan fasilitas servis. Perancangan ini mengoptimalkan pencahayaan dan penghawaan alami pada fasilitas-fasilitas yang ada dengan menata sirkulasi dan kondisi bangunan terhadap iklim tropis, sehingga memperoleh suatu perancangan yang baik untuk kenyamanan ruang dalam dan ruang luar.
\end{abstract}

\begin{abstract}
Pastor Bonus Middle Seminary, located in the YPPK Yos Sudarso High School complex in Merauke, currently does not have complete facilities in terms of space function and optimal building arrangement. Redesigning the Bonus Bonus Middle Seminary in Merauke is expected to be able to develop the existing seminary site area, so that it can meet the needs of facilities that are suitable for function and zoning. The purpose of this research is to redesign the Merauke Bonus Pastoral Seminary which prioritizes clarity of functions and zoning through a modern tropical architectural approach, as well as arranging building mass according to the site's shape by considering circulation. The method used in this study is the method of observation / direct observation to the location of the study, interviews with the seminary and Archdiocese of Merauke which provide direction for regional development and capacity building of seminary facilities. The results obtained are used as a reference for improving management facilities, educational facilities, talent talent facilities, religious facilities, residential facilities and service facilities. This design optimizes the lighting and natural airing of existing facilities by arranging the circulation and condition of the building against the tropical climate, so as to obtain a good design for the comfort of inner space and outside space.
\end{abstract}

Kata-kunci: Redesign.,Seminary., Pastor Bonus., Merauke.

\section{Pendahuluan}

Keberadaan sekolah katolik sudah dikenal sejak lama dan sampai saat ini menjadi salah satu bidang karya gereja yang utama.Perkembangan sekolah katolik telah memberikan warna dansumbangan yang berarti dalam sejarah perkembangan gereja.Seiring dengan perkembangan situasipendidikan di Indonesia, tidak jarang pada akhirnya sekolah katolikmengalami degradasi nilai-nilai tradisional yang luhur [1].
Sekolah Katolik ialah suatu sekolah yang dipimpin oleh otoritas gerejawi yang berwenang atau oleh badan hukum gerejawi publik atau yang diakui demikian oleh otoritas gerejawi melalui dokumen tertulis [2]. Salah satu sekolah Katolik yang diakui oleh otoritas gerejawi adalah sekolah seminari (sekolah bagi calon pastor Katolik) yang didirikan secara legitim, menurut hukum mempunyai status badan hukum dalam Gereja [3].

Seminari merupakan benih panggilan rohani yang ada pada seseorang, disemaikan dengan pendidikan di seminari. Di dalam Gereja Katolik, fungsi dari seminari adalah sebagai wadah dalam 
mempersiapkan orang-orang yang menyediakan dirinya bagi tugas keimanan atau suatu tugas dalam masyarakat Katolik di Indonesia. Dalam seminari terdapat jenjang Seminari Menengah setingkat SMA dan Seminari Tinggi setingkat perguruan tinggi. Pada seminari menengah para siswa seminari juga diberikan pendidikan formal seperti siswa-siswa sekolah menengah pada umumnya.

Kabupaten Merauke merupakan pusat Keuskupan Agung di Papua Selatan dengan luas wilayah pelayanan mencapai Kabupaten Mappi dan Kabupaten Boven Digoel dengan jumlah gereja 190 dan umat Katolik 92.171 [4].

Seminari Menengah Pastor Bonus berlokasi di kompleks SMA YPPK Yos Sudarso Merauke. Para siswa Seminari Menengah Pastor Bonus masih menggunakan gedung SPG (Sekolah Pendidikan Guru lama), yang sekaligus sebagai tempat hunian dan aktivitas keagamaan. Sedangkan untuk memperoleh pendidikan umum sesuai peraturan pemerintah, siswa seminari mengikuti program pendidikan umum di SMA YPPK Yos Sudarso Merauke. Hal ini disebabkan sarana prasarana pendidikan umum belum memenuhi kebutuhan seminari. Selain itu ketersediaan fasilitas seminari belum memberikan fungsi ruang maupun penataan bangunan secara optimal.

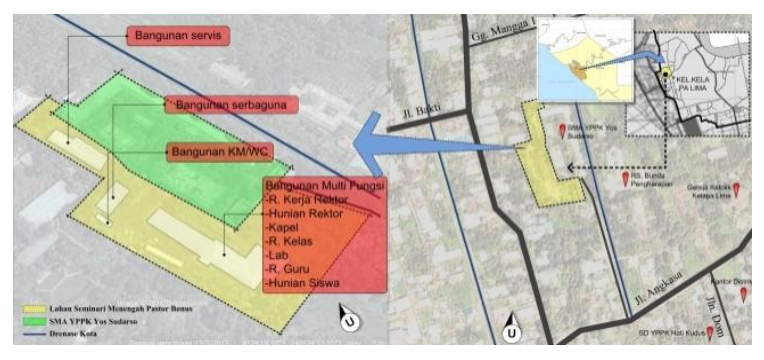

Gambar 1.

Lokasi eksisting Seminari Menengah Pastor Bonus di Merauke.

Pada gambar diatas menunjukan bangunan multi fungsi (ruang rektor, hunian rektor, ruang kapel, ruang kelas, ruang guru, Lab dan hunian siswa seminari) yang secara zonasi kurang baik, karena ruang hunian dan kapel memerlukan ketenangan dalam privasi sendiri. Sementara keseluruhan bangunan perlu ditata ulang untuk memperoleh susunan bangunan sesuai dengan bentuk tapak yang terlihat tidak simetris. Permasalahan ini menyebabkan perlu adanya redesain atau mendesain ulang dalam pengertian membuat revisi dalam penampilan dan fungsi [5]. Dengan adanya Redesain Seminari Menengah Pastor Bonus tidak terlepas dari keinginan pihak Seminari Menengah Pastor Bonus yang mengharapkan peningkatan fasilitas (Hasil survei wawancara dengan Rektor Seminari Menengah Pastor Bonus, Pastor Minarto Pr, 2015), dan sesuai dengan Peraturan Menteri Pendidikan Nasional Republik Indonesia Nomor 24 Tahun 2007 Tentang Standar Sarana dan Prasarana Untuk Sekolah Dasar/Madrasah Ibtidaiyah (SD/MI), Sekolah Menengah Pertama/Madrasah Tsanawiyah (SMP/MTs), dan Sekolah Menengah Atas/Madrasah Aliyah (SMA/MA) [6]. Sedangkan dari pihak Keuskupan Agung Merauke memberikan solusi pada pengembangan luasan lahan ke arah utara Seminari Menengah Pastor Bonus, karena lahan tersebut milik Keuskupan Agung Merauke (Hasil survei wawancara dengan Uskup Agung Merauke, Mgr Nikolaus Adi Seputra MSC, 2016).

Redesain Seminari Menengah Pastor Bonus di Merauke diharapkan juga dapat mengembangkan luasan lahan seminari yang ada, sehingga dapat memenuhi kebutuhan fasilitas yang sesuai fungsi dan zonasi. Dalam pengembangan Redesain Seminari Menengah Pastor Bonus di Merauke dipertimbangkan pada kondisi Kabupaten Merauke yang memiliki iklim tropis, untuk suasana ruang dan kawasan yang nyaman pada iklim. Selain itu kenyamanan dalam aktivitas belajar, berdoa maupun aktivitas seminari lainnya sangat diperhatikan dengan kondisi iklim Merauke. Dimana bangunan yang direncanakan di iklim tropis akan dikombinasikan dengan konsep bergaya modern yang akan meningkatkan kualitas tampilan bangunan. Sehingga tercipta keharmonisan antara bangunan bergaya modern dengan kondisi iklim Merauke. Maka pendekatan yang digunakan adalah "Arsitektur Modern Tropis". Dengan demikian Seminari Menengah Pastor Bonus di Merauke diharapkan menjadi wadah yang nyamanan untuk calon rohaniwan Katolik. 


\section{Metode Penelitian}

Langka awal yang dilakukan untuk mengetahui permasalahan-permasalahan yang menjadi pokok permasalahan dalam perancangan ini yaitu dengan metode deskriptis (mendeskripsikan) yaitu metode yang digunakan untuk mencari unsur-unsur, ciri-ciri, sifat-sifat atau fenomena. Metode ini dimulai dengan mengumpulkan data dan menganalisis data. Metode deskriptis dalam pelaksanaannya dilakukan melalui teknik survey, studi kasus, studi komparasi dan analisis documenter [7,8].

Metode pengumpulan data yang gunakan, yaitu; observasi, wawancara dan studi pustaka. Peneliti melakukan wawancara terhadap narasumber dari Rektor Seminari Menengah Pastor Bonus Pastor Minarto Pr dan Uskup Agung Merauke Mrg Nikolaus Adi Seputra MSC. Hasil dari wawancara tersebut digunakan peneliti sebagai dasar pertimbangan dalam perancangan Seminari Menengah Pastor Bonus.

Peneliti juga mendapat data primer, data kuantitatif yang secara fisik dapat diketahui ukuran atau jumlahnya, antara lain:

1. Dimensi ruang-ruang di Seminari Menengah Pastor Bonus.

2. Data jumlah siswa Seminari Menengah Pastor Bonus.

Lokasi perancangan Seminari Menengah Pastor Bonus terdapat di Kelurahan Kelapa Lima Jalan Angkasa. Pemilihan lokasi ini berdasarkan BWK kota Merauke dan atas pendapat Uskup Agung Merauke Mrg Nikolaus Adi Seputra SMC. Lokasi perancangan termasuk dalam pemanfaatan kawasan Pendidikan dan Pelayanan Umum.

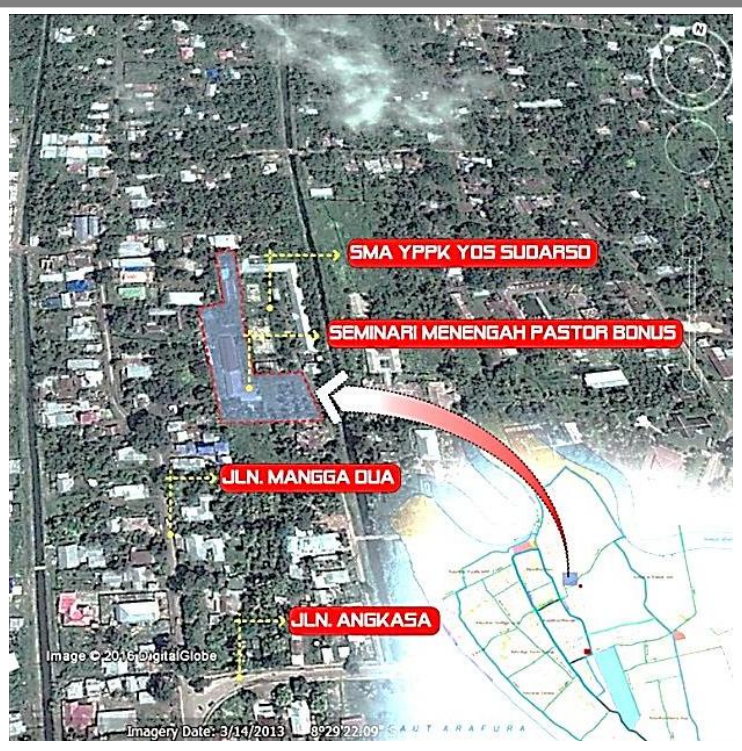

Gambar 2.

Lokasi penelitian Seminari Menengah Pastor Bonus

\section{Pembahasan dan Hasil}

Redesain Seminari Menengah Pastor Bonus di Merauke menjadikan fungsi ruang sebagai salah satu fokus dasar perancangan. Untuk itu dilakukan analisis fungsi yang bertujuan me wujudkan fungsi sesuai dengan penggunaan ruang. Analisis fungsi menurut tingkatan kegiatan terbagi menjadi tiga jenis yaitu, fungsi primer, fungsi sekunder dan fungsi servis. Ada dua fungsi utama yang akan dibahas yaitu fungsi pendidikan menengah dan fungsi penunjang seminari.

Berdasarkan fungsi kegiatan terdapat fasilitasfasilitas sebagai berikut:

1. Pengelola Administrasi

2. Edukasi (SMA-KPA)

3. Edukasi (Agama Minat/Bakat)

4. Religi

5. Hunian

6. Pelayanan Servis 


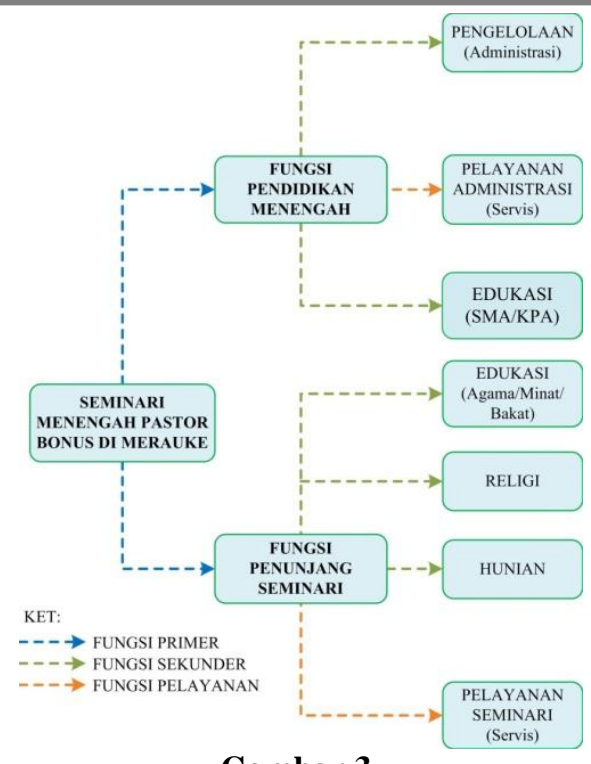

Gambar 3.

Skema fungsi Seminari Menengah Pastor Bonus di Merauke

Tabel 1. Jenis Fasilitas

\begin{tabular}{lll}
\hline Jenis Fasilitas & Satuan & Luas \\
\hline Fasilitas Pengelola & M2 & 585 \\
Fasilitas Edukasi & M2 & 517 \\
Fasilitas Edukasi & M2 & 960,49 \\
Religi,Minat dan Bakat & & \\
Fasilitas Religi & M2 & 636 \\
Fasilitas Hunian & M2 & 990,2 \\
Fasilitas Servis & M2 & 617,631 \\
Vasilitas Area Parkiran & M2 & 445,2 \\
Jumlah & M2 & 4751,5 \\
\hline
\end{tabular}

Berdasarkan BWK Kab. Merauke untuk fasilitas pendidikan ketentuan yang digunakan dalam hal mendirikan bangunan yaitu standar perbandingan Koefisien Dasar Bangunan adalah 50\%-20\%. Dengan demikian luas lahan yang dibutuhkan untuk Seminari Menengah Pastor Bonus Merauke dengan perbandingan Koefisien Dasar Bangunan (KDB) 30\% dan Open Space area tidak terbangun $70 \%$ akan dihitung dengan rekapitulasi luas fasilitas $4751,5 \mathrm{~m}^{2}$ sebagai berikut:

Koefisien Dasar Bangunan

(KDB) 30\% $4751,5 \quad \mathrm{~m}^{2}$

Area Tapak Tidak Terbangun

Open Space (OS) 70\%

Jadi luas Open Space (OS) yang

dibutuhkan

(OS 70\% / KDB 30\% /Luas

$\mathrm{m}^{2}$

Fasilitas $\left.4751,5 \mathrm{~m}^{2}\right)$

$(\mathrm{KDB}+\mathrm{OS})$
Dari hasil perhitungan di atas diketahui luas lahan yang dibutuhkan untuk Seminari Menengah

Pastor Bonus Merauke adalah $15838 \mathrm{~m}^{2}$ atau \pm 1,6 Ha

\subsection{Analisis Zonasi}

Analisis zonasi merupakan salah satu langkah awal yang dilakukan untuk menyelesaikan permasalahan penataan massa bangunan. Dimana diketahui bentuk tapak seminari kurang simetris yang menjadi persoalan utama dalam menentukan letak massa bangunan. Oleh karena itu dilakukan analisis zonasi untuk mengetahui posisi letak massa bangunan yang baik terhadap kondisi fisik tapak yang terlihat tidak simetris. Untuk mempermudah peletakan posisi zonasi yang baik dibagi berdasarkan analisis zona secara makro dan mikro, Dari analisis zonasi diperoleh peletakan zona-zona sebagai berikut:

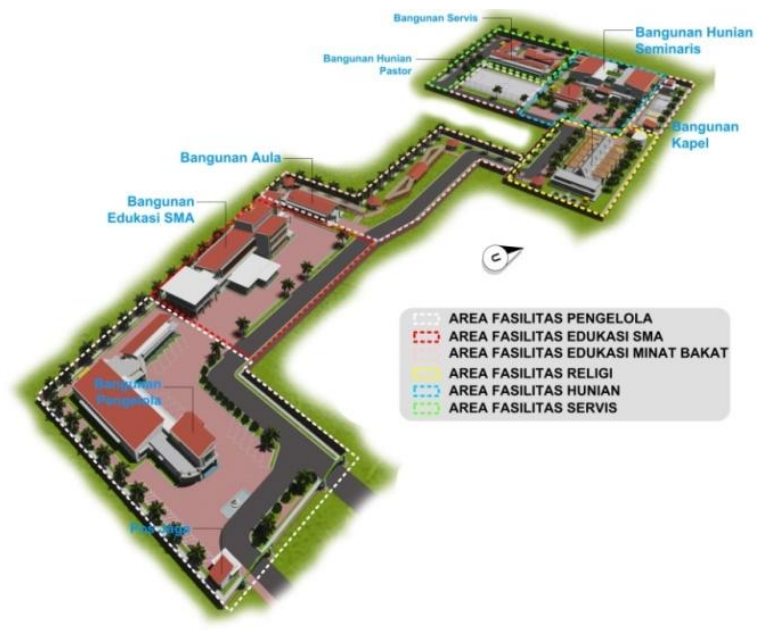

Gambar 4.

Perletakkan Zona

\subsection{Garis Sepadan Bangunan (GSB)}

Garis Sepadan Bangunan dilihat berdasarkan klarifikasi jenis jalan yang ada. Dari lokasi tapak memiliki jalan utama yang jauh, sehingga GSB disesuaikan dengan kebutuhan tapak. Namun pada bagian timur tapak terdapat drainase kota, yang diambil garis sepadan drainase 8 - 12 m (Revisi Tata Ruang Willayah Kota Merauke), karena drainase dilalui oleh kategori jalan kolektor sekunder. 


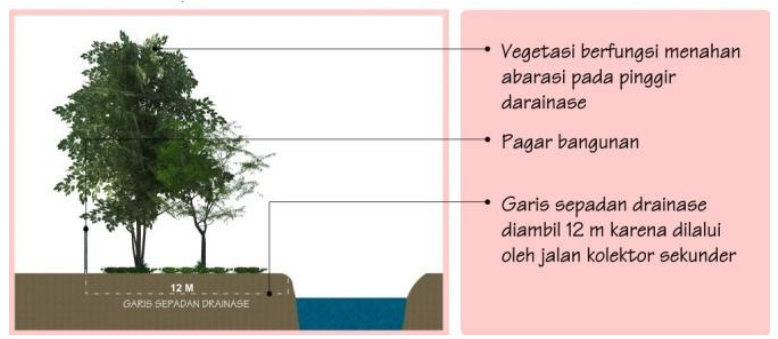

Gambar 4.

Ilustrasi Garis Sempadan Bangunan

\subsection{Pencapaian}

Untuk mencapai tapak telah ditentukan lewat analisis pencapain. Pencapaian utama dilalui lewat Jalan Angkasa, sedangkan pencapain servis dilaui lewat Jalan Mangga dua.

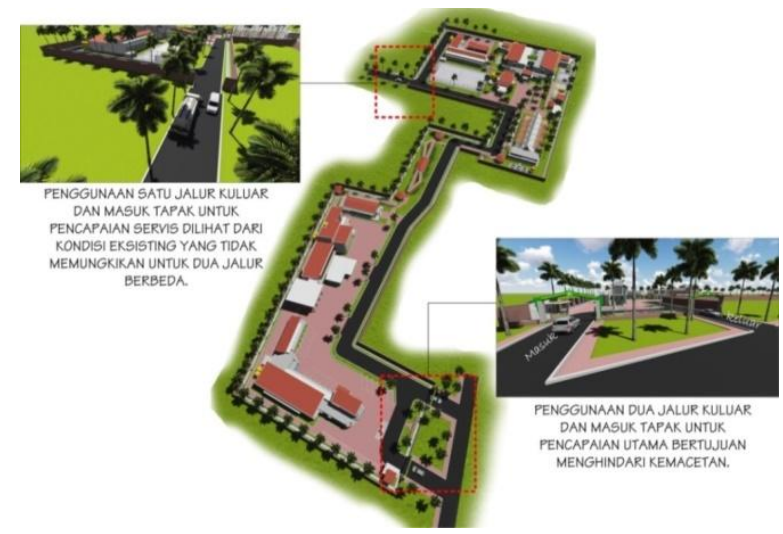

Gambar 5. Pencapain

\subsection{Orientasi Matahari}

Matahari dimaanfatkan sebagai kebutuhan penerangan didalam bangunan pada siang hari. Dalam perancangan ini bukaan bangunan disediakan untuk menerima cahaya matahari dengan mempertimbangkan luasan bukaan. Namun efek panas yang dihasilkan matahari menjadi persoalan dalam bangunan untuk itu solusinya adalah, penggunaan material kayu pada sun shading, penggunaan material kaca penahan panas, penggunaan kanopi dan vegetasi yang berfungsi meredam panas matahari.

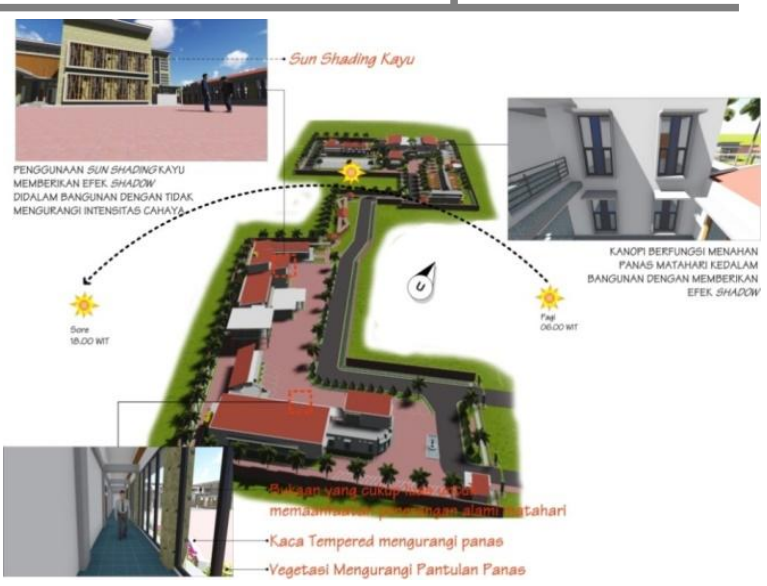

Gambar 6. Orientasi Matahari

\subsection{Orientasi Angin}

Dalam rancangan ini angin diperlukan untuk kebutuhan kenyamanan baik dalam ruangan maupun luar ruang. Namun yang dimanfaatkan adalah angin dengan tekanan yang sedang atau rendah. Bukaan pada bangunan dalam perancangan ini menggunakan ventilasi dan jendela sebagai alur udarah.

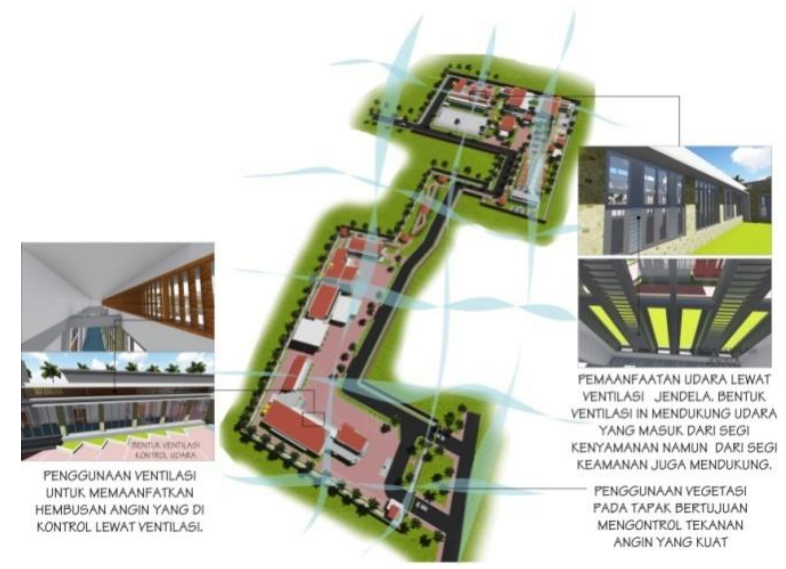

Gambar 7. Orientasi Angin

\subsection{Curah Hujan}

Dalam perancangan ini menggunakan atap miring dan atap dak yang mengonrol debit air yang dimaanfaatkan ke dalam bak penampung melalui selokan yang mengelilingi tapak berfungsi menyalurkan air hujan yang tidak tertampung di arahkan ke drainase kota. 


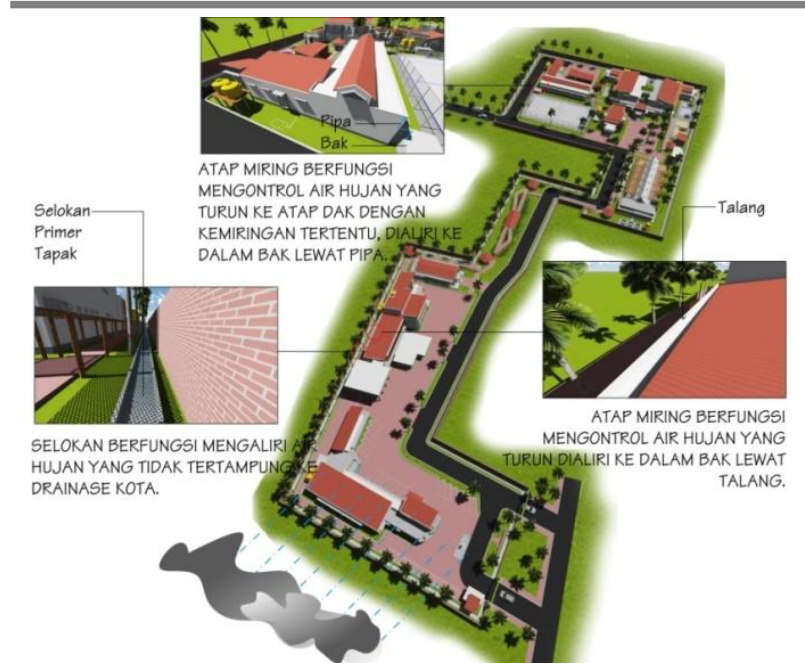

Gambar 8. Curah Hujan

\subsection{Perancangan Sirkulasi Dalam Tapak}

Sirkulasi dalam tapak perlu diatur karena bentuk tapak yang tidak simetris dan faktor bangunan bermasa banyak. Pola yang digunakan dalam menentukan sirkulasi dalam tapak mengikuti bentuk dan susunan masa bangunan. Sirkulasi dalam tapak terbagi menjadi sirkulasi kendaraan dan sirkulasi manusia.

\subsection{Pandangan Kedalam Tapak}

Telah dijelaskan sebelumnya pada analisis view, bahwa titik potensi view kedalam tapak yang mempengaruhi rencana ketinggian bangunan dengan kebutuhan perancangan. Potensi view memberikan kejelasan bangunan atau vokal point dari bangunan dalam tapak.

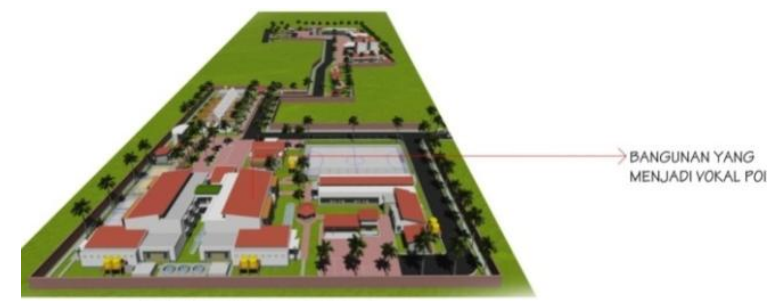

TAMPAK UTARA

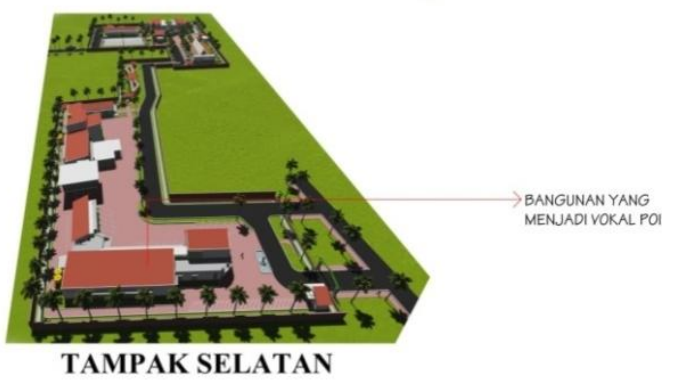

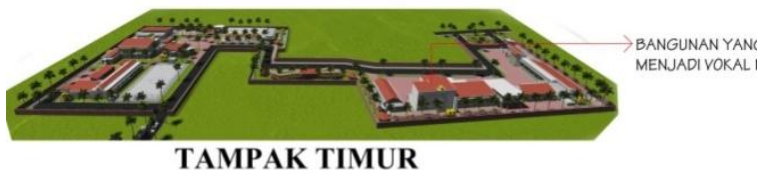

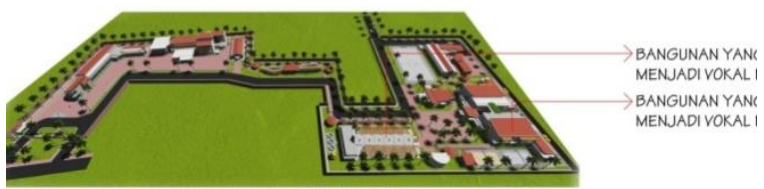

TAMPAK BARAT

Gambar 9. Pandangan Kedalam Tapak

\subsection{Perancangan Vegetasi}

Bagi perancangan vegetasi menjadi bagian penting sebagai pelengkap bangunan. Selain itu vegetasi juga mempunyai fungsi dan kelebihan masing-masing yang dapat dimaanfaatkan bagi lingkungan. Dalam perancangan ini terdapat vegetasi pengarah, peneduh, menguri tekanan angin dan penyaring debu

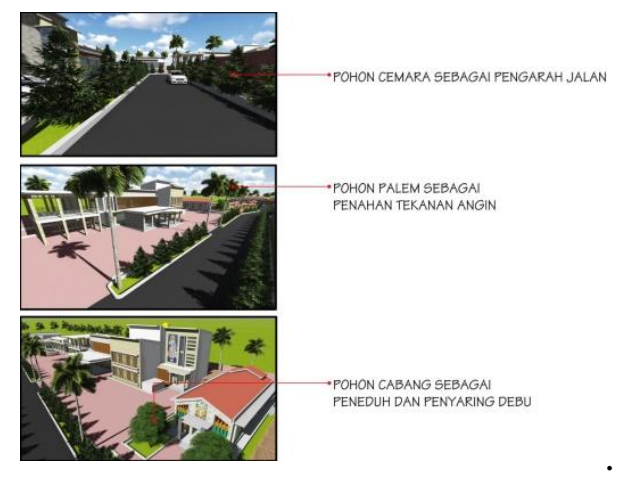

Gambar 10. Perancangan Vegetasi

\subsection{Pola Tata Massa Bangunan}

Pola tata massa bangunan mengikuti bentuk tapak. Pola yang digunakan dalam bentuk tata massa bangunan yaitu, pola linier yang menghubungkan setiap bangunan berdasarkan hirarki ruang yang dimulai dari umum ke khusus. Pendekatan modern tropis 


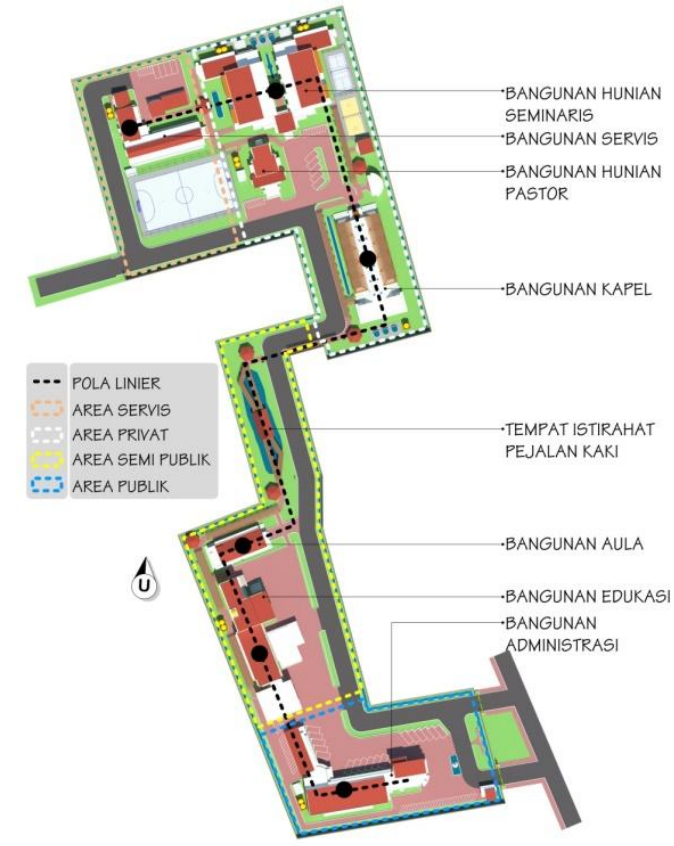

Gambar 11. Pola Tata Massa Bangunan

\subsection{Bentuk dan Tampilan Bangunan}

Pendekatan yang digunakan dalam perancangan ini yaitu, modern tropis memberikan Dasar pemilihan bentuk dan tampilan bangunan melihat dari kondisi tapak. Bentuk dipengaruhi oleh bentuk tapak yang memanjang dan tidak simetris, sehingga bentuk bangunan pada umumnya persegi panjang. Selain itu bentuk bangunan dipertimbangkan dari luas lahan dan sirkulasi dalam tapak. Sedangkan tampilan bangunan didapat lewat anilisis-analisis yang telah dilakukan sebelumnya.

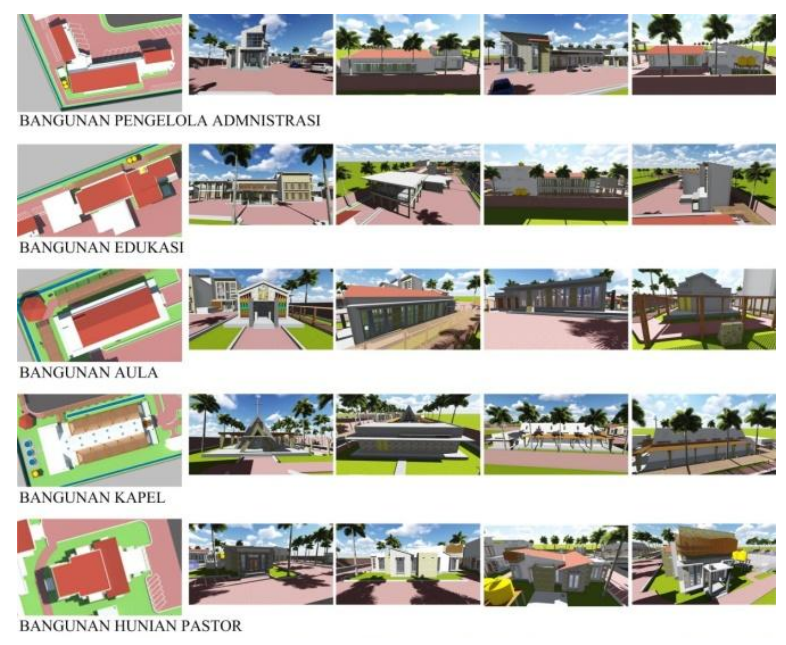

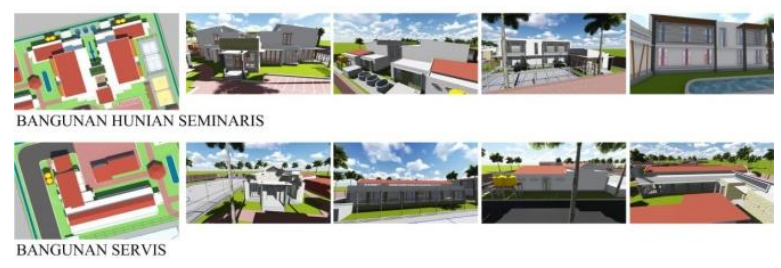

Gambar 12. Bentuk dan Tampilan Bangunan

\subsection{Perancangan Utilitas}

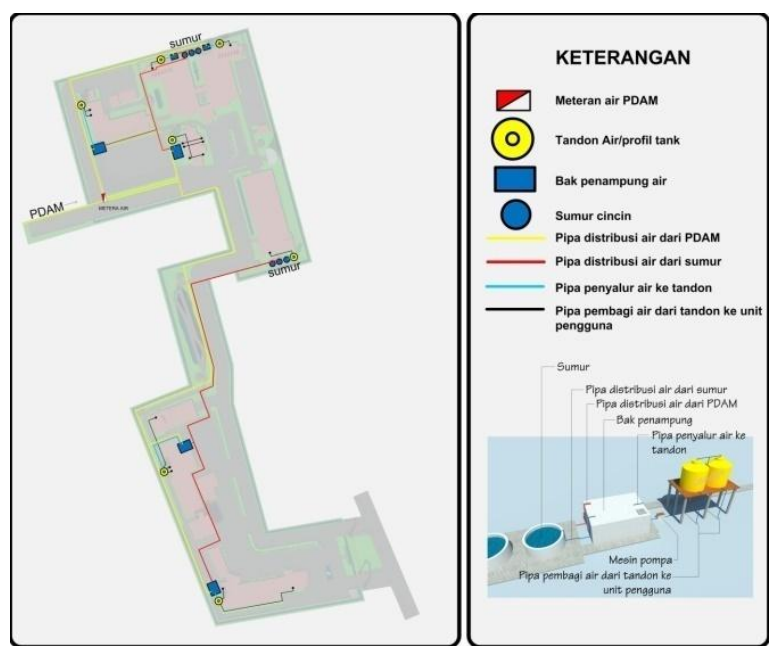

Gambar 13. Perancangan Sistem Penyediaan Air Bersih

3.14 Perancangan Sistem Pembuangan

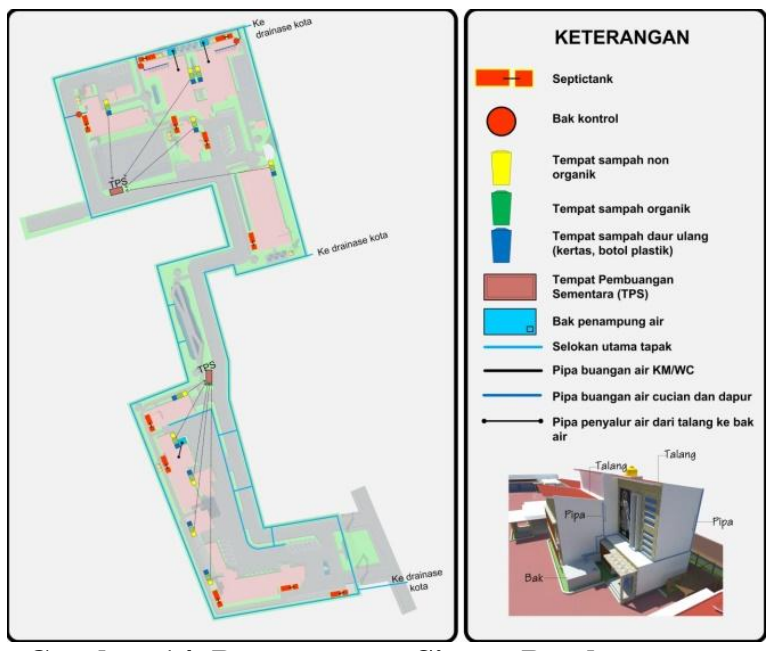

Gambar 14. Perancangan Sistem Pembuangan 


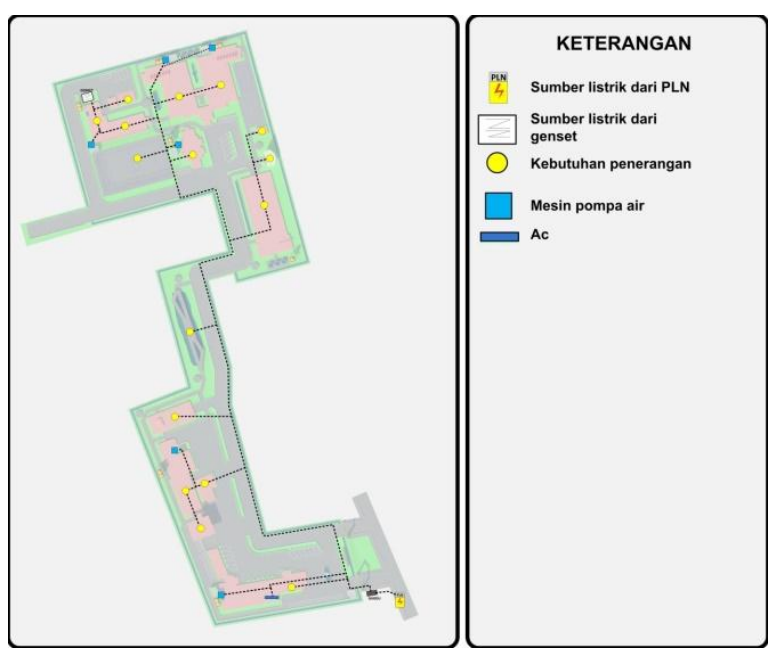

Gambar 15. Perancangan Sistem Tenaga Listrik

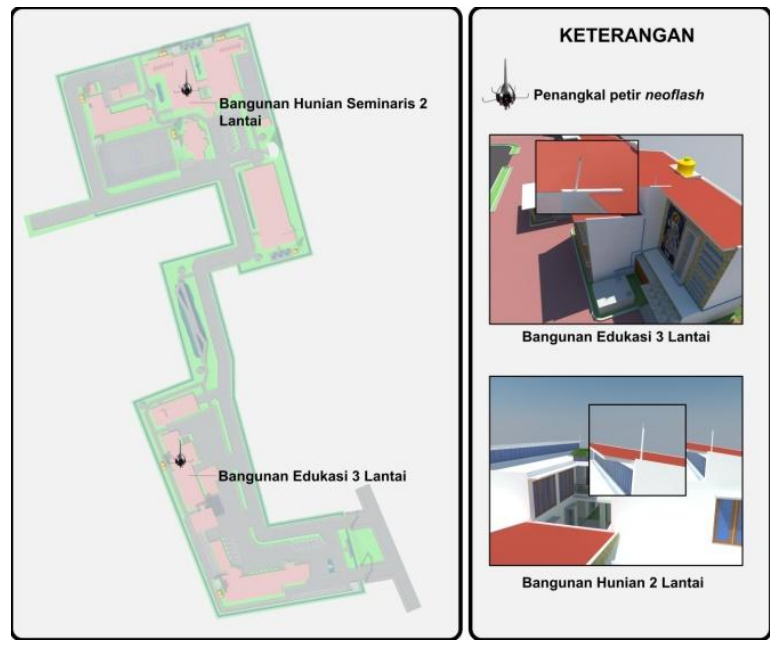

Gambar 16. Perancangan Sistem Penangkal Petir

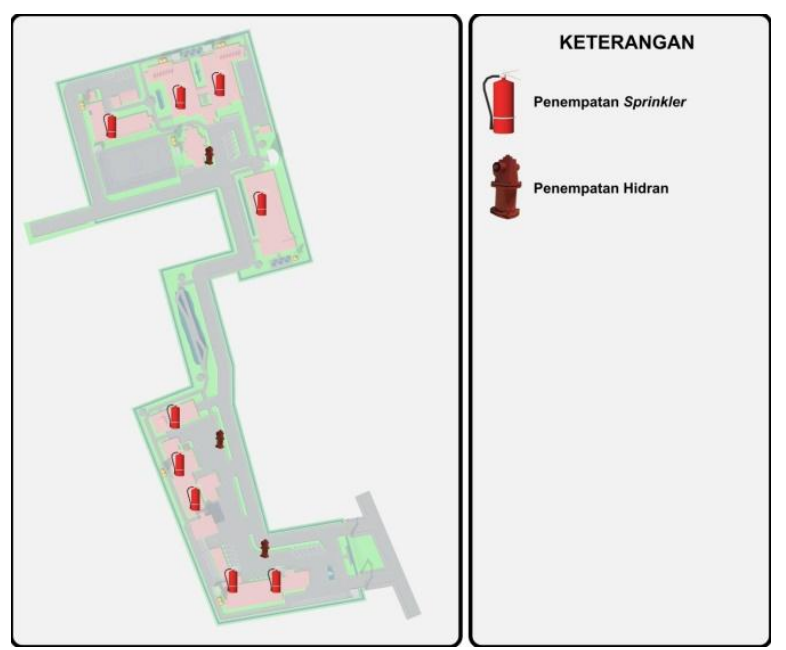

Gambar 17. Perancangan Sistem Pemadam Kebakaran
3.15 Perancangan Struktur

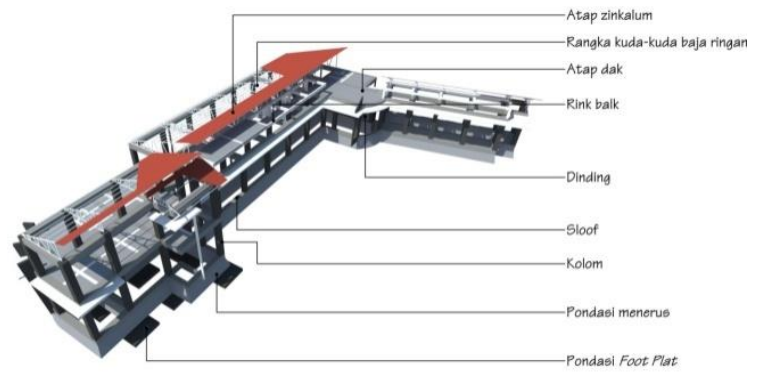

Gambar 18. Struktur Bangunan Pengelola

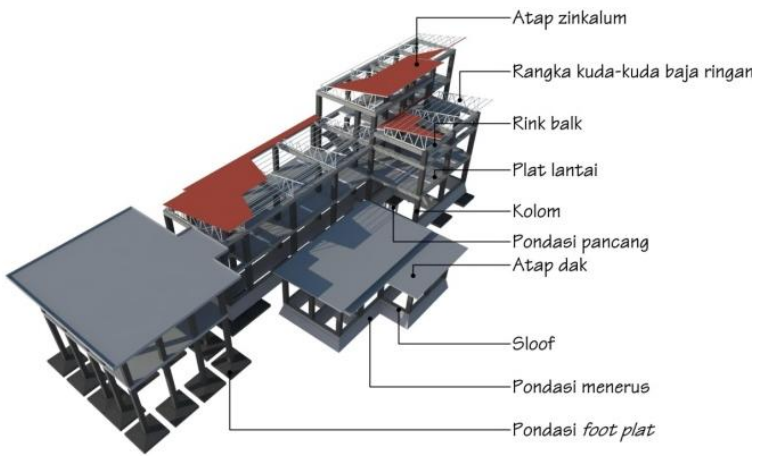

Gambar 19. Struktur Bangunan Edukasi

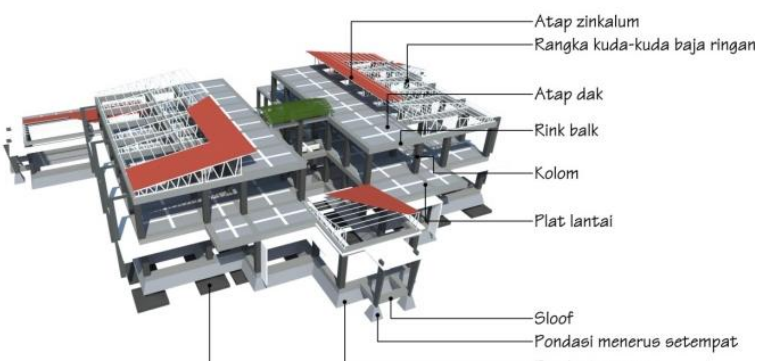

Gambar 20. Struktur Bangunanas Henengian

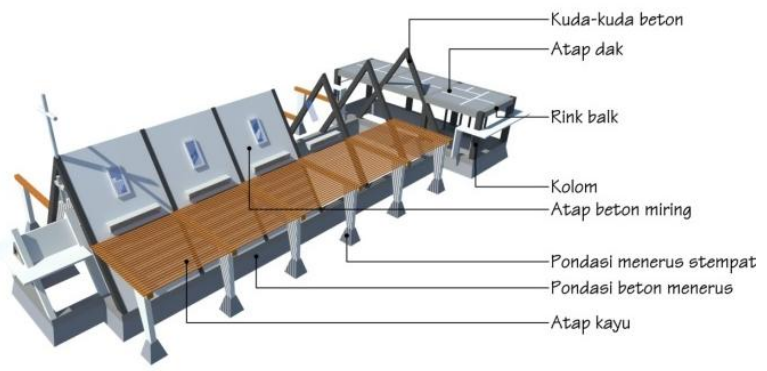

Gambar 21. Struktur Bangunan Kapel 


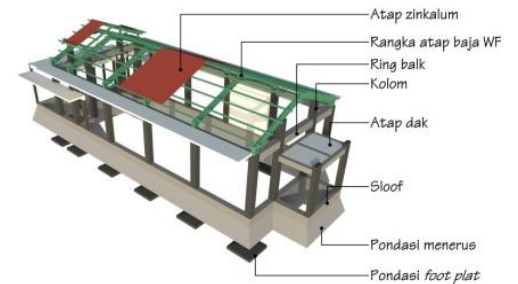

Gambar 21. Struktur Bangunan Aula

\section{KESIMPULAN}

Meredesain fasilitas pendidikan menengah dan fasilitas penunjang Seminari Menengah Pastor Bonus di Merauke yang mengutamakan kejelasan fungsi dan zonasi. Fungsi Seminari Menengah Pastor Bonus di Merauke terbagi menjadi tiga jenis yaitu; fungsi primer, fungsi sekunder dan fungsi servis. Fungsi primer terbagi menjadi dua jenis yaitu; fungsi pendidikan menengah dan fungsi penunjang seminari. Fungsi primer terbagi lagi dalam beberapa jenis fungsi yang disebut dengan fungsi sekunder dan masingmasing fungsi primer didukung oleh satu fungsi servis. Berikut merupakan penjabaran dari fungsi Seminari Menengah Pastor Bonus, fungsi primer yaitu fungsi pendidikan menengah dan fungsi penunjang seminari. Fungsi pendidikan menengah terbagi menjadi dua fungsi sekunder yaitu; Pengelolaan (Administrasi) dan Edukasi (SMA/KPA) dan didukung oleh satu fungsi servis yaitu; Pelayanan Adminisrasi. Fungsi penunjang seminari terbagi menjadi tiga fungsi sekunder yaitu; Edukasi (Agama/Minat/Bakat), Religi, Hunian dan didukung oleh satu fungsi servis yaitu Pelayanan Seminari. Zonasi Ruang Pengelola yaitu: Zona Publik (Pos Jaga, Parkiran Pengunjung dan Pengelola, Lobby, R. Tamu dan WC Tamu), Zona Semi Publik (R. Rektor + WC, R. Kepsek + WC, R. Rapat, R. Guru, R. Tata Usaha, R. Arsip, R. Konseling, R. UKS SMA dan $R$. Osis SMA), Zona Privat (R. Istirahat Pengelola) dan Zona Servis (Pantry, WC Pengelola, Gudang dan Loker). Zonasi Ruang Edukasi yaitu: Zona Semi Publik (R. Kelas, R. KPA, R. Istirahat Kelas, Laboratorium dan Perpustakaan) dan Zona Servis (WC Siswa danWC Guru). Zonasi Ruang Edukasi Religi, Minat \& Bakat Siswa yaitu: Zona Semi Publik (Lap. Volly, Lap. Takraw, Lap. Futsal dan R. Aula) dan Zona Servis (WC Pria/Wanita dan Gudang). Zonasi Ruang Religi yaitu: Zona Semi
Publik (R, Umat dan Goa Maria), Zona Privat (R. Sakaristi dan R. Adorasi) dan Zona Servis (WC Pria dan Wanita). Zonasi Ruang Hunian yaitu: Zona Publik (Parkiran Khusus), Zona Semi Publik (R. Tamu Pastor, R. Tamu Seminaris dan R. Nonton Pastor), Zona Privat ( R. Tidur Rektor+ $\mathrm{WC} / \mathrm{KM}, \mathrm{R}$. Tidur Warek $+\mathrm{WC} / \mathrm{KM}, \mathrm{R}$. Tidur Pastor Pengasuh + WC/KM, R. Tidur Siswa, R. Tidur KPA, R. Nonton Siswa, R. Baca Siswa dan R. Baca KPA) dan Zona Servis (WC/KM/Tempat Cuci Pakaian Kelas IPA dan

WC/KM/Tempat Cuci Pakaian Kelas IPS/KPA). Zonasi Ruang Servis yaitu: Zona Semi Publik (R. Makan Bersama), Zona Privat (R. Ganti + R. Tidur) dan Zona Servis (Dapur Masak, WC, KM, R. Cuci Pakaian, R. Seterika, R. Genset, Parkiran Servis, Gudang Makanan dan Garasi Mobil/Motor). Pendekatan Arsitektur Modern Tropis diterapakan melalui: pemanfaatan sinar matahari untuk pencahayaan alami, pemanfaatan angin untuk penghawaan alami, pengolahan air hujan dan penataan vegetasi dan penerapan bentuk persegi pada bangunan guna mencerminkan arsitektur modern.

Penataan masa bangunan dipertimbangkan dengan sirkulasi yang menjadi salah faktor penentu dalam menempatkan posisi dan orientasi massa bangunan. Setiap orientasi bangunan mengarah ke sirkulasi utam tapak. Suasana kawasan dan ruang yang terjaga keyamananya.

\section{Referensi}

[1] Runtuwene,Lastiko. 2011. "Makna Sekolah Katolik". Jurnal: Bimas Katolik Kanwil Kementerian Agama Prov. Sulut bekerja-sama dengan Yayasan Pendidikan Katolik Keuskupan Manado.

[2] Kitab Hukum Kanonik 1938

[3] Kitab Hukum Kanonik 238

[4] Merauke dalam Angka 2014

[5] Arianda, M. Taufik. 2015. "Desain Museum Provinsi Kalimatan Barat". Jurnal: Arsitektur Universitas Tanjungpura, Nomor 1. Volume 3

[6] Peraturan Menteri Pendidikan Nasional Republik Indonesia Nomor 24 Tahun 2007 Tentang Standar Sarana dan Prasarana Untuk Sekolah Dasar/Madrasah Ibtidaiyah (SD/MI), Sekolah Menengah Pertama/Madrasah Tsanawiyah (SMP/MTs), dan Sekolah Menengah Atas/Madrasah Aliyah (SMA/MA).

[7] Moleong, Lexy J. Metode Penelitian Kualitatif. Bandung: PT Remaja Rosda Karya. (2017) 
[8] Sugiyono,2016. Metode Penelitian Kuantitatif, Kualitatif, dan R\&D. Alfabeta Bandung. 